


\title{
Does having digital skills really pay off?
}

- Having the highest levels of skills in problem solving using ICT (information and communication technologies) increases chances of participating in the labour force by six percentage points compared with adults who have the lowest levels of these skills, even after accounting for various other factors, such as age, gender, level of education, literacy and numeracy proficiency, and use of e-mail at home.

- Adults without ICT experience are less likely to participate in the labour force; if they are employed, they earn less than adults with ICT experience, after accounting for various other factors.

- Experience in using ICT has a particularly large impact on participation in the labour force and earnings in Australia, England/Northern Ireland (UK) and the United States.

- Workers who use ICT frequently have substantially higher wages than those who do not use ICT often.

With the widespread diffusion of ICT, it is often claimed that "digital skills" - the capacity to use ICT devices and applications to access and manage information and solve problems - have become essential skills. Is this really true? Do people who are highly proficient in these skills have better chances of participating in the labour force and earn higher wages than those who are less proficient?

The Survey of Adult Skills (a product of the OECD Programme for the International Assessment of Adult Competencies, PIAAC) provides some answers by testing the ability of adults to solve problems that require the use of common computer applications, such as e-mail, web browsers and spreadsheets.

\section{Higher proficiency in solving problems using digital devices is associated with higher rates of participation in the labour force.}

In all countries, the labour force participation rate is lowest among adults with no experience in using ICT: only $47 \%$ of these adults participate in the labour force. By comparison, $90 \%$ of adults who performed at the highest levels of proficiency (Level 2 or 3 in the Survey of Adult Skills) in using digital devices to solve problems and 76\% of adults who have very low proficiency (below Level 1) participate in the labour force. (Adults who perform below Level 1 have some ICT skills but cannot use these skills to solve common problems encountered when working in digital environments, such as browsing the web.)

Figure 1 - Labour force participation, by proficiency in solving problems using ICT Adults aged 25 to 65, OECD average

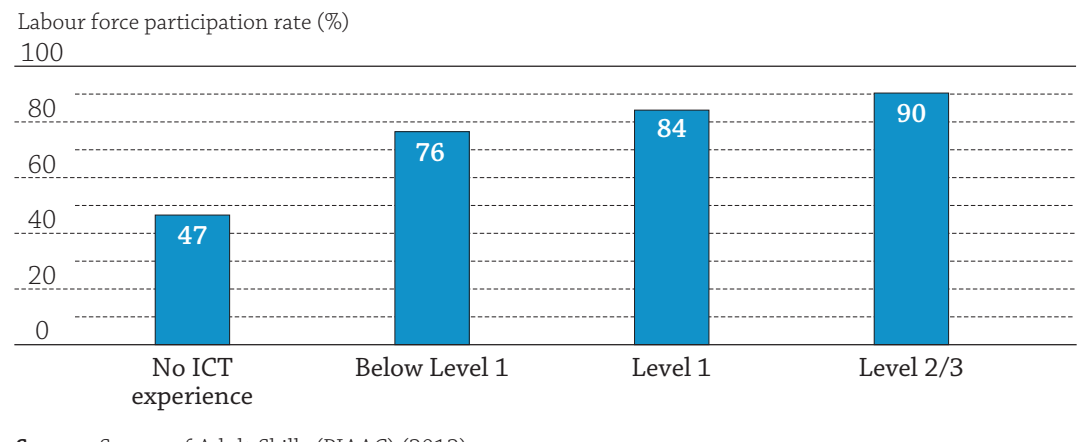

Source: Survey of Adult Skills (PIAAC) (2012). 
It is possible that the difference in labour force participation rates is the result of some other factors related to the use of ICT, such as having a higher level of education or using digital applications regularly at home. But even after accounting for adults' age, gender, level of education, proficiency in literacy and numeracy, and use of e-mail at home, the difference in labour force participation rates between adults with the highest levels of skills in problem solving using ICT and those who are proficient at the lowest level is 6 percentage points, while the difference in labour force participation rates between this latter group and those with no experience in using ICT is 15 percentage points. This suggests that proficiency in problem solving using ICT, in itself, has a positive impact on labour force participation, regardless of all the other factors considered, including literacy skills.

\section{Figure 2 - How labour force participation is affected by problem-solving proficiency and lack of experience in using ICT \\ Difference in the rate of labour force participation between groups, OECD average}



Note: Adjusted differences take socio-demographic characteristics (age, gender, foreign-born status, years of education and marital status), literacy and numeracy proficiency, e-mail use at home and reading/writing/ numeracy use at home into account.

$\square$ Source: Survey of Adult Skills (PIAAC) (2012).

\section{The relationship between digital skills and participation in the labour force is much stronger in some countries.}

The labour force advantage associated with being more proficient in solving problems using ICT is greatest in England/Northern Ireland (UK), Ireland, the Netherlands and Norway. In England/Northern Ireland (UK) and Ireland, the rate of labour force participation among adults performing at Level 2 or 3 on the survey is 17 percentage points higher than the rate of labour force participation among adults performing at or below Level 1, after accounting for other factors. In Norway, the difference in labour force participation rates between the two groups is 11 percentage points.

The disadvantage associated with having no experience in using ICT is larger in many countries. In England/Northern Ireland (UK), the labour force participation rate among adults with no ICT experience is 33 percentage points lower than that of adults who performed at the lowest level in problem solving, even after taking various socio-demographic characteristics into account. This difference is also large in the United States (31 percentage points) and Australia (28 percentage points). 


\section{Workers with no experience in using ICT suffer a wage penalty.}

Workers who have no experience in using ICT earn $18 \%$ less per hour, on average, than those who perform below Level 1 in the survey. Even after taking other factors into account, such as age, gender, educational attainment, proficiency in literacy and numeracy, and use of e-mail at work, having no experience in using ICT still has a negative impact on hourly wages. An adult with no experience in using ICT earns $6 \%$ less per hour than an adult who performs at even the lowest level of proficiency.

Figure 3 - Wage premium and digital skills

Percentage difference in mean hourly wages between different groups, OECD average

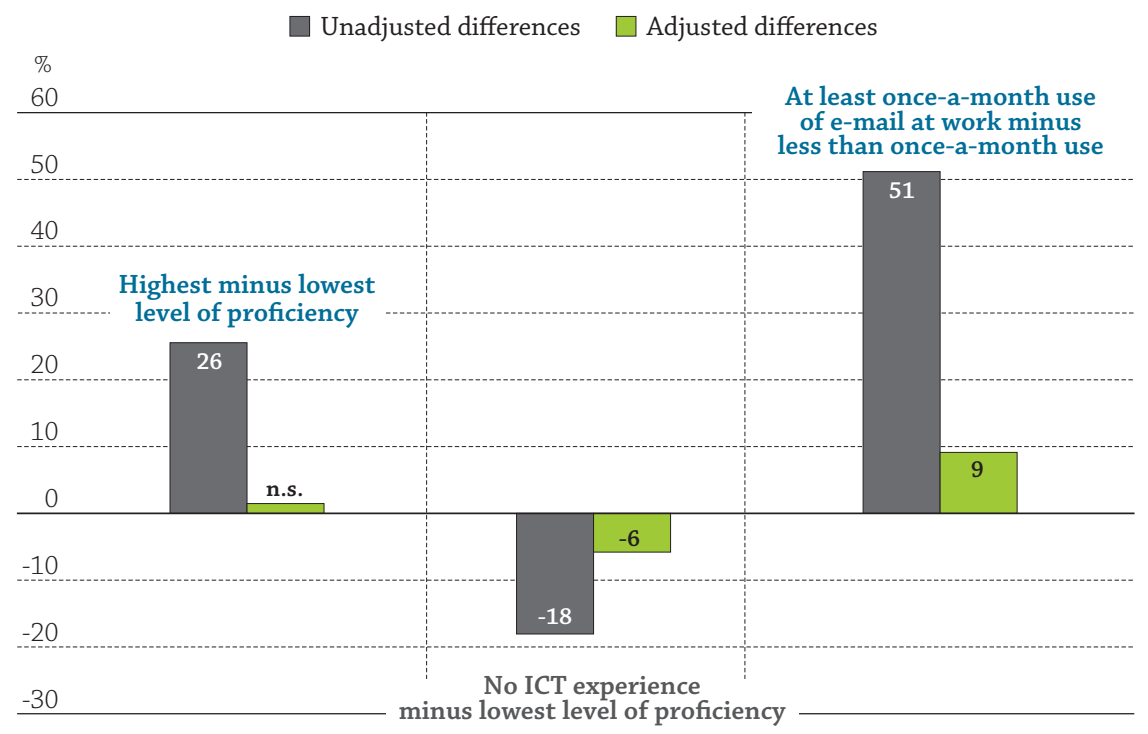

Note: Adjusted differences take socio-demographic characteristics (age, gender, foreign-born status, years of education, marital status and years of experience), literacy and numeracy proficiency, e-mail use at work, reading/writing/numeracy use at work, and occupation into account.

Source: Survey of Adult Skills (PIAAC) (2012).

Workers who are proficient at Level 2 or 3 in problem solving using ICT earn $26 \%$ more per hour than those performing below Level 1. However, in these cases, the higher wages largely reflect other factors, such as workers' educational attainment, proficiency in literacy and numeracy, and the use of e-mail at work. When comparing workers with similar socio-demographic characteristics, levels of proficiency in literacy and numeracy, and frequency of e-mail use at work, the wage advantage for those who perform at Level 2 or 3 in problem solving compared to those who perform below Level 1 shrinks to $4 \%$. If other factors, such as the type of occupation and the frequency of reading, writing and using numeracy skills on the job, are also taken into account, wage differences disappear entirely. In other words, workers with better skills in problem solving in digital environments are paid more because they also tend to have better cognitive skills, in general, and because they work in jobs that involve greater use of information-processing skills.

\section{More frequent use of ICT is associated with higher wages.}

The importance of using ICT in the workplace is illustrated by the fact that the average salary per hour for workers who use e-mail regularly at work is significantly higher than that of workers who use e-mail less frequently. Those workers who use e-mail frequently in their jobs earn $9 \%$ more per hour, on average, than workers who are equally proficient in literacy, numeracy and problem solving, but who use e-mail infrequently. Thus, simply having acquired ICT skills is not enough; those skills must be used in the workplace if they are to make a difference in wages. However, the use of ICT at work seems to vary across countries. In Nordic countries, around $80 \%$ adults use a computer at work while only around 55\% of adults or less in Italy, Poland, the Russian Federation, the Slovak Republic and Spain use a computer at work. 
Figure 4 - Percentage of workers who use a computer at work

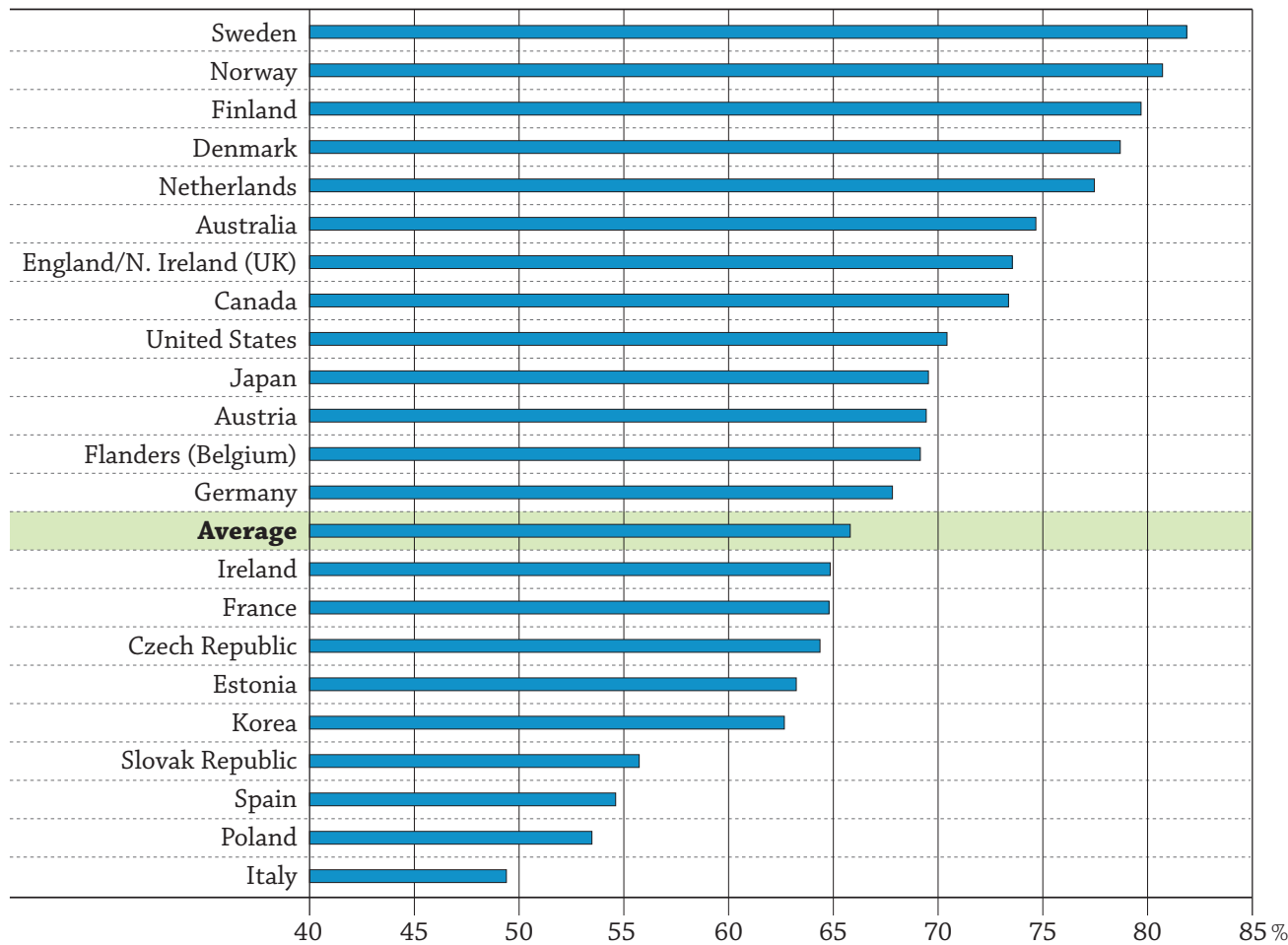

Source: Survey of Adult Skills (PIAAC) (2012).

The bottom line: Being able to access and manage information using ICT are essential skills in today's increasingly knowledge-based economies. Higher proficiency in these skills is rewarded with a greater likelihood of participating in the labour force, and more frequent use of ICT at work is rewarded with higher wages than is observed among adults who are equally proficient in literacy and numeracy, but who have less proficiency in this skill or use ICT infrequently. Since adults with no ICT experience are at a considerable disadvantage in employment prospects and wages, policy makers can consider ways of ensuring that all individuals have access to ICT training, whether during compulsory education or in adult learning activities.

\section{For more information}

OECD (2015), Adults, Computers and Problem Solving: What's the Problem?, OECD Skills Studies, OECD Publishing, Paris, http://dx.doi.org/10.1787/ $\underline{9789264236844-e n}$.

\section{Visit}

www.oecd.org/site/piaac/

Education Indicators in Focus

PISA in Focus

Teaching in Focus

\section{Contact}

Ji Eun Chung (JiEun.Chung@oecd.org)

William Thorn (William.Thorn@oecd.org)

Photo credits: @ Konstantin Chagin/Shutterstock • ๑ Mint Images/Tim Robbins / Getty Images • ๑ momentimages/Tetra Images/Inmagine LTD

This paper is published under the responsibility of the Secretary-General of the OECD. The opinions expressed and the arguments employed herein do not necessarily reflect the official views of OECD member countries.

This document and any map included herein are without prejudice to the status of or sovereignty over any territory, to the delimitation of international frontiers and boundaries and to the name of any territory, city or area.

You can copy, download or print OECD content for your own use, and you can include excerpts from OECD publications, databases and multimedia products in your own documents, presentations, blogs, websites and teaching materials, provided that suitable acknowledgment of OECD as source and copyright owner is given. All requests for commercial use and translation rights should be submitted to rights@oecd.org. 